\title{
Research of the Reduced Mass of the Railway Track
}

\author{
D. Kurhan ${ }^{*}$, Y. Leibuk ${ }^{2}$ \\ ${ }^{1}$ Dnipro National University of Railway Transport named after Academician \\ V. Lazaryan, Department of Track and Track Facilities \\ Lazaryan st. 2, 49010, Dnipro, Ukraine \\ *E-mail: kurhan.d@gmail.com
}

\section{${ }^{2}$ Joint Stock Company "Ukrainian railways", Branch "Center of Engineering Structures for Construction and Repair" Zaliznychne Highway, 5B, 01103, Kyiv, Ukraine}

Abstract: In an overall view, a vehicle is described as a system of bodies interconnected by elastic and dissipative couplings. Bodies have a mass concentrated at a point, the movement of which describes their motion. Certain difficulties arise when introducing a railway track into such models. While interacting with the rolling stock, the track operates as an elastic body, and its mass is specified as reduced to the point of interaction. The purpose of this work is to provide a reasonable value of the reduced mass of the railway track depending on its parameters. The task is solved by applying a spatial model of dynamic deformations of the railway track on the basis of the elasticity theory. Such an approach makes it possible to determine which part of the railway track interacts with the wheel based on the propagation of deformations as elastic waves.

Keywords: railway; track and rolling stock interaction; reduced mass; wave propagation; stress-strain state

\section{Introduction}

Nowadays, in most cases, mathematical models of movement of railway rolling stock are based on the system of Lagrange equations of the second kind. In an overall view, a vehicle (a car or a locomotive) is described as a system of bodies 
interconnected by elastic and dissipative couplings. Bodies have a mass concentrated at a point. The displacement of centers of mass at each time step in system solution of differential equations is the result of the simulation, which makes it possible to obtain forces, stresses, and other necessary motion parameters. Such an approach describes the dynamic processes of rolling stock with adequacy sufficient for almost the entire list of relevant modern tasks $[1,2,3,4,5,6]$, etc. Certain difficulties arise when introducing a railway track into such models. Considering that the track when interacting with the rolling stock operates at elastic deformations, to divide it into separate masses that are not compressed, but move, it is possible only with a number of conventions. It is known that increasing the detailing of the track does not solve this problem, especially for the description of such layers as ballast and soil.

Many developments, most of which use the latest scientific approaches, are devoted to this study of the stress-strain work of the under sleeper base. So, for example, work [7] makes the analysis of a modern condition of such researches. More often it is the finite element method (FEM) [8,9], in addition, it is the method of discrete elements [10], computed tomography [11], the process of elastic waves propagation $[12,13]$, and others.

Most railway transport tasks require a comprehensive assessment in the track and rolling stock interaction. Therefore, the approach in which two different mathematical models are consistently applied is widely used. First, a model with a detailed description of the vehicle and a minimum sufficient representation of the track makes it possible to obtain the forces of interaction, then the model of the railway operation from the applied forces allows to determine the stresses and strains in the body of the track. In any case, for models based on the system of Lagrange equations of the second kind, it remains the need to set the mass of the railway track elements.

It can be agreed that for many tasks the value of the track mass does not affect the results as much as the stiffness and dissipation indices [14], and to some extent, it is a formal need to divide the system into separate objects. Still, a tool is needed to determine it. Therefore, the purpose of this study is to substantiate the values of the mass of the railway track for such mathematical models depending on its design and operating conditions [15].

\section{Theory of the method for determining the reduced mass}

Such elements of the railway track as rail, ballast layer, roadbed do not have appropriate (determinate) geometric dimensions in length. Therefore, representing them as an object (or set of objects) that has a link with a wheel (or wheelset with an axle), the length is conditionally limited to the part that participates in the interaction. It is clear that the physical mass of an object, with the dimensions, thus determined, 
is not yet required for introduction into the mathematical model, because this object operates at an elastic deformation, the magnitude of which is not identical to the displacement of the center of mass.

One of the forms of representation of the Lagrange equation of the second kind is to write it through the kinetic energy of the system $(T)$

$$
\frac{d}{d t}\left(\frac{\partial T}{\partial \dot{q}_{i}}\right)-\frac{\partial T}{\partial q_{i}}=Q_{i},
$$

where $q_{i}$ - generalized coordinate; $Q_{i}$ - generalized force; $t$ - time factor.

The kinetic energy of an elastic system consisting of elements of mass $d m$, which is deformed at a speed $V_{i}$ is equal to

$$
T=\int_{m} \frac{V_{i}^{2}}{2} d m
$$

Ensuring the correspondence of kinetic energies, the reduced mass of the system "railway track" will be so concentrated in the point of mass, which, moving with a velocity of the reference point (wheel-rail interaction point), has the same kinetic energy that all elements of the elastic system have while their moving (deformation):

$$
m_{R}=\frac{1}{V_{0}^{2}} \int_{m} V_{i}^{2} d m \text {. }
$$

Assuming that $\frac{d z_{i}}{d t} / \frac{d z_{0}}{d t}=\frac{z_{i}}{z_{0}}$ it can be seen:

$$
m_{R}=\frac{1}{z_{0}^{2}} \int_{m} z_{i}^{2} d m
$$

where $z_{0}$ - vertical deflection at the reference point (wheel-rail interaction point); $z_{i}$ - vertical deformation of the $i$-th element, from them the system consists of, for which the reduced mass is determined.

In this work, the task was to form the reduced mass of the railway track as a single object: a support that interacts with the wheel. Therefore, masses of the rail, sleepers, ballast, and a roadbed can be considered in the wheel and at reduced to the wheelrail interaction point. The obtained components of the reduced mass of the railway track can be regrouped into objects with other details.

Elastic vertical deflections of the rail can be determined by formulas:

$$
\begin{gathered}
z_{i}=\frac{P k}{2 U}(\cos k x+\sin k x) e^{-k x} ; \\
k=\sqrt[4]{\frac{U}{4 E I}},
\end{gathered}
$$


where $P$ - the calculated force of the wheel pressure on the rail $[16,17,18] ; U-$ deformation modulus of a track; the distance from the wheel-rail interaction point to the $i$-th cross-section of the rail; EI is rail stiffness (product of the deformation modulus and inertia moment of the rail), $e$ is the Euler's number (mathematical constant), $x$ - distance on rail from the force application point.

Substituting these expressions to formula (4) it can be obtained:

$$
m_{r}=2 M_{r} \int_{0}^{\infty}(\cos k x+\sin k x)^{2} e^{(-2 k x)},
$$

where $m_{r}$ - the reduced mass of the rail; $M_{r}$ - is mass per unit length of the rail, $\mathrm{kg} / \mathrm{m}$.

And in the final formula is:

$$
m_{r}=\frac{3 M_{r}}{2 k} .
$$

Sleepers are elements that have known dimensions and known mass. If reinforced concrete sleepers are taken into account, their elastic deformations can be neglected. Then formula (8) can be used to determine the reduced mass of the assembled rails and sleepers. For this, the value $M_{r}$ will be equal to the mass of the running meter of the assembled rails and sleepers as a whole, attributed to one wheel (i.e. the mass of the rail, the mass of fasteners on one rail, and the mass of half of the sleepers).

Further research was aimed at determining the mass of the under sleeper base (ballast and roadbed), which are involved in the oscillations/vibrations of each rail support at any moment of time.

To solve this problem, a spatial model of dynamic deformations of the railway track based on the elasticity theory $[13,19]$ was applied. One of the basic elements of such a model is to determine the geometry of stress propagation (and appropriate deformations) in the half-space of the railway track from the action of external load (rolling stock wheels). The geometry of stress propagation is described as a wave process through the set of vectors $\{\vec{u}\}$. The lengths of the vectors are determined at each time step $d t$ for all possible directions of propagation, which are specified by angles $\alpha \in[0 ; 0.5 \pi]$ and $\gamma \in[0 ; 2 \pi]$, describing the half-space (Fig. 1). 


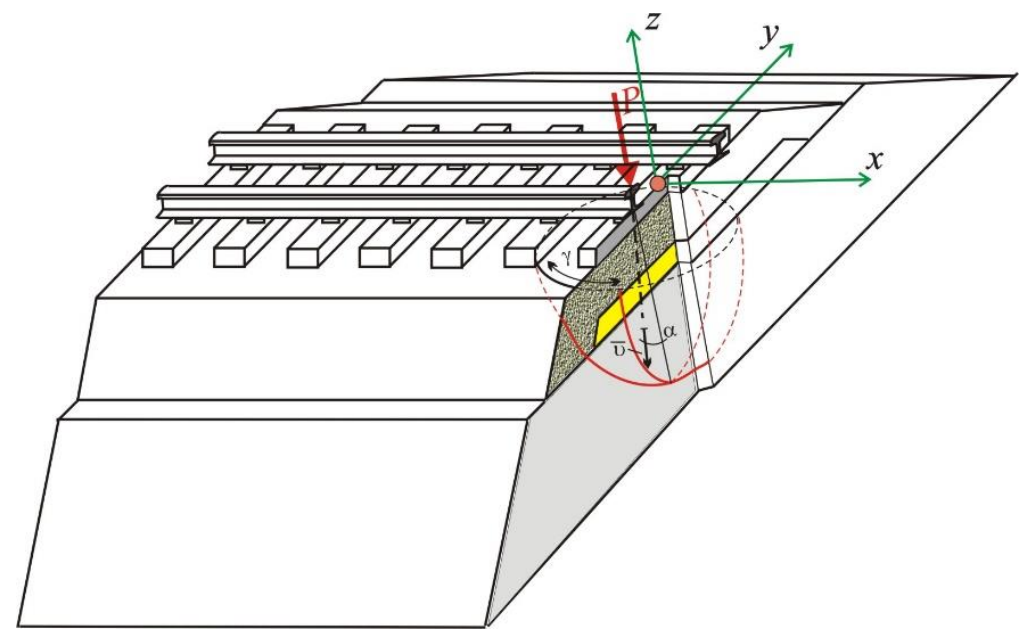

Figure 1. Propagation vector of deformation in the selected coordinate system

The set of vectors forms a surface that corresponds to the stress propagation front at a given point in time of interaction. Fig. 2 shows such surfaces in the ballast under the sleeper exported from the computer implementation of the model. For visualization, the example uses an enlarged modeling step (the time between surfaces is $0.0004 \mathrm{~s}$ ). The usual calculation step is $0.00002 \mathrm{~s}$.
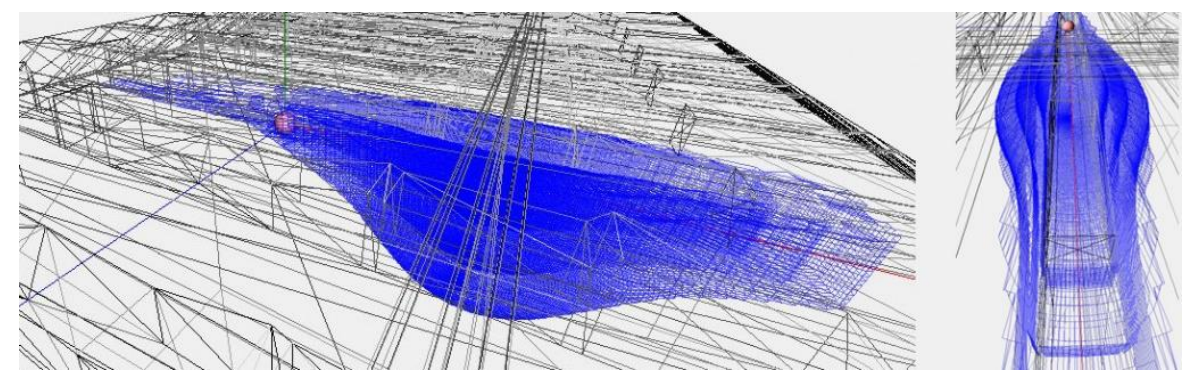

Figure 2. The example of the forming the geometry of stress propagation front at a given point in time of interaction

Propagation geometry is limited by object boundaries. When vectors move from one object to another, the propagation rate is adjusted by changing their physical properties.

As the stress wave propagates, the half-space of the railway track is divided into separate segments, and each such segment consists of a set of vectors that had formed 
it. Four adjacent vectors delimit a single element of the segment. The result of the calculations is the stress and strain for each element. The mass of such an element can be defined as

$$
d m=\rho S \frac{1}{4} \sum_{i}^{i+3}\left|\vec{u}_{i}\right|,
$$

where $\rho$-is the density of a substance; $S$ - is the wall square of the element (Fig. 3).

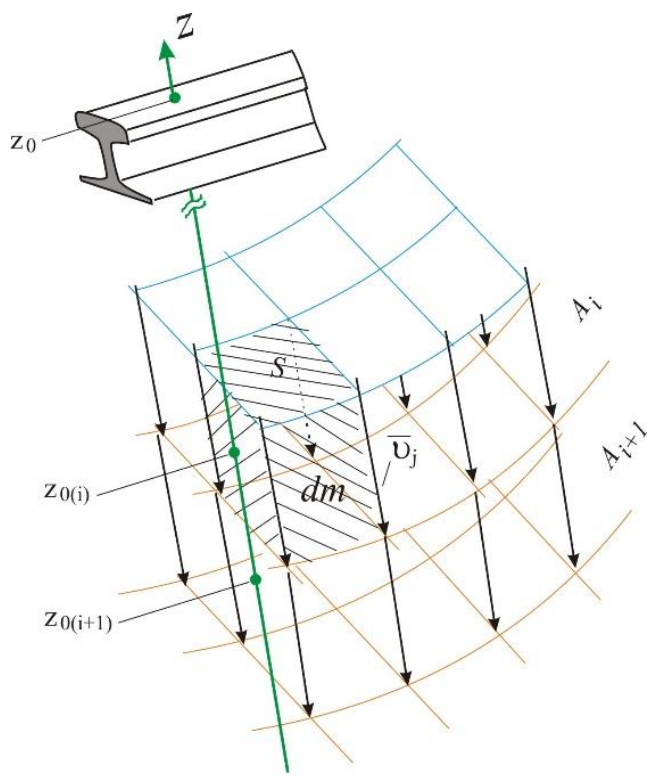

Figure 3. Calculation scheme for determining the reduced mass

This approach allows to obtain exactly the space of the railway track that is involved in the interaction, in the form of a set of elements for which their masses and vertical deformations are known.

Given the structure adopted in the model, the calculation of the reduced mass is performed in the following sequence.

1. The under sleeper base includes two objects of the system: ballast layer: $\left(\omega_{b}\right)$ and soil $\left(\omega_{s}\right)$. From the force applied to the rail, deformations propagate and after several time steps of the simulations are transmitted from the sole (and partially from the side surfaces) of the sleeper to the ballast. Further propagation of deformations forms the calculation spheres $\left(A_{i}\right)$, each of which is the space between the beginnings and ends of the vectors in the current calculation step (see Fig. 3), with regard to the constraints of the object by boundaries: 


$$
A_{i}=\left\{\vec{u}_{j} \mid \vec{u}_{j} \in \omega\right\} .
$$

Thus, the active (i.e. those involved in the interaction) volumes of objects (ballast and soil) are formed:

$$
\omega=\left\{A_{i}\right\} .
$$

2. The mass (full) $d m_{j}$ and vertical deformation $z_{j}$ of each element, involved in the interaction are fixed.

3. The reduced mass of each sphere can be determined, with the reference point to its vertical axis

$$
m_{R(i)}=\frac{1}{z_{0(i)}^{2}} \sum_{j} d m_{j} z_{j}^{2},
$$

where $z_{0(i)}$ - vertical deformation of the sphere along the axis (see Fig. 3).

3. The reduced mass of the layer to the wheel-rail interaction point is determined

$$
m_{R(\omega)}=\frac{1}{z_{0}^{2}} \sum_{i \epsilon \omega} m_{R(i)} z_{0(i)}^{2} .
$$

\section{The results of simulation of the railway track operation to determine the reduced mass}

The reduced mass of the under sleeper base depends on many initial characteristics in the system. Therefore, further calculations will be performed and analyzed as options with a change of the main characteristics in certain ranges.

The following option of the under sleeper base is accepted as primary: ballast crushed stone $50 \mathrm{~cm}$ thick, with the modulus of deformation of $200 \mathrm{MPa}$ and density of $1600 \mathrm{~kg} / \mathrm{m}^{3}$; a roadbed from the soil with the modulus of deformation of $35 \mathrm{MPa}$ and a density of $1400 \mathrm{~kg} / \mathrm{m}^{3}$. Given that the calculation of masses for the elements involved in the interaction, and their deformations are carried out on the spheres from the point of force application, it is possible to obtain and monitor the gradual gain of the reduced mass along with the depth of the base. Fig. 4 shows the increase in the mass of the under sleeper base reduced to the wheel-rail interaction point with the depth. The sleeper sole is taken as the zero marks of the depth here and in further calculations. At the mark of $0.5 \mathrm{~m}$, there is a change in the contour of the growth curve of the reduced mass, which is explained by the transition from the ballast layer to the soil. Gradually with depth, the elastic deformations of the soil decrease, which, accordingly, leads to almost zero growth intensity of the reduced mass. 


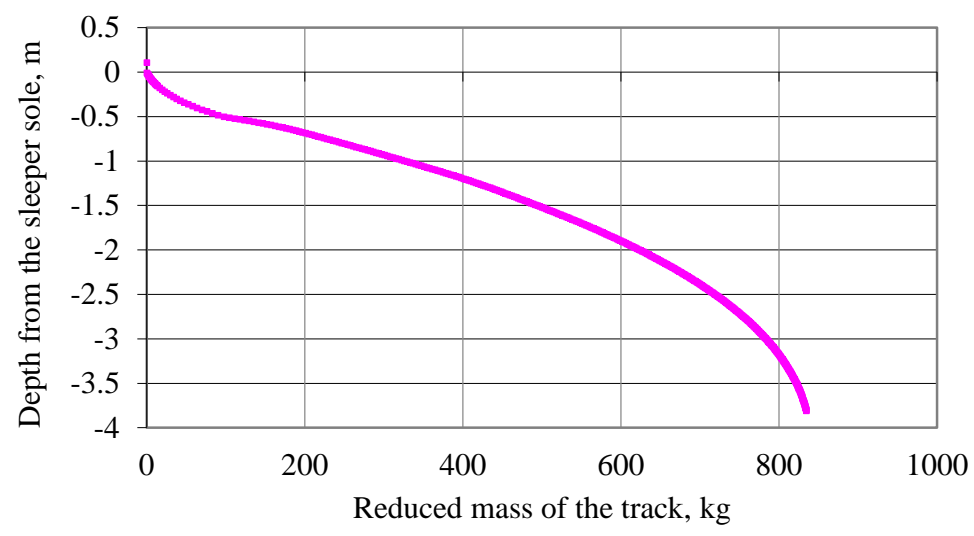

Figure 4. The example of determining the reduced mass of the under sleeper base

For a sufficiently large range of speeds, the interaction time does not matter, because the load (wheel) is always in the area of already realized deformations [20]. The dependence of the reduced mass of the railway track on the speed of movement appears under conditions when the rail deflection under the wheel does not have time to reach the maximum value and there is a difference between dynamic and static deflections. Therefore, the results of this and the most further calculations do not depend on the speed of motion. This issue will be discussed further in more details.

It is also clear that the results of the reduced mass for impactless motion do not depend on the external load value (within the linearity of the stress-strain relationship).

Next, the impact of various factors on the reduced mass of both individual layers of the railway track and the under sleeper base as a whole can be considered.

\subsection{Ballast thickness}

Keeping the original data of the previous example (the basis for further research can be considered), the impact of the ballast layer thickness will be analyzed. Fig. 5 shows the dependence of the reduced mass of the ballast on its thickness (the range from 40 to $60 \mathrm{~cm}$ was taken into account). 


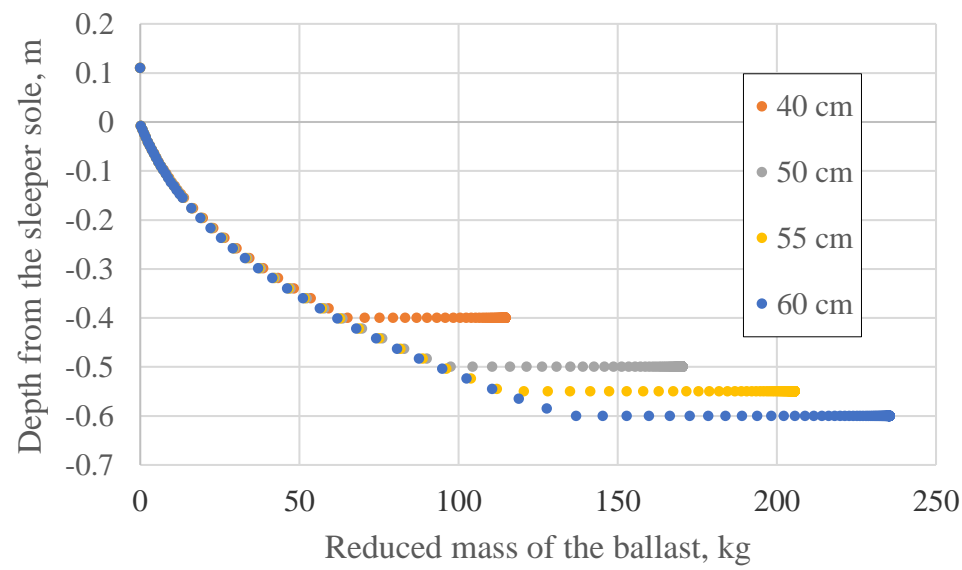

\section{Figure 5. $\quad$ Impact of ballast thickness on its reduced mass}

For each option, a gradual set of mass on the depth of the under sleeper base is shown, which corresponds to the involvement of increasing volumes of the ballast. The sleeper sole is taken as the zero marks on the vertical axis. Upon completion of the ballast layer, its reduced mass continues to grow due to the propagation of the interaction along the track (linear segment in Fig. 5). But, given that the stresses in the ballast and, accordingly, its deformation decreases rapidly, the intensity of addition/supplement to the reduced mass is close to zero.

Fig. 6 shows the accumulation of the reduced soil mass in accordance with the considered options of ballast thickness.

For uniformity of understanding, the soil surface is taken as zero depth in Fig. 6 in all options. With depth, all large volumes of soil are involved in the interaction, which leads to an increase in the reduced mass, but on the other hand, the deformations gradually dampen with depth, which initially reduces and then stops the intensity of the reduced mass.

It should be noted that for the option with a greater thickness of the ballast layer, stresses, and, accordingly, the deformation in the soil will be less. But at the same time, there is an increase in the reduced mass of soil. This is due to the fact that the option with a greater thickness of the ballast layer has a larger contact area of the ballast with the roadbed, which increases the volume of soil involved in the interaction. 


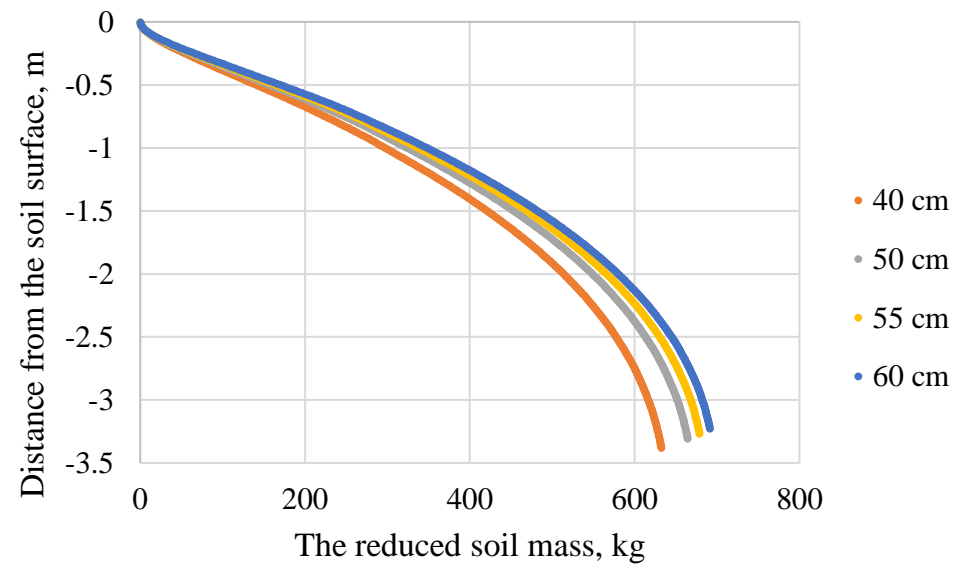

Figure 6. Impact of ballast thickness on the reduced soil mass

\subsection{Soil deformation modulus}

On the basis of the option accepted as basic (see above), change of the soil deformation modulus in the range from 25 to $45 \mathrm{MPa}$ is considered (Fig. 7).

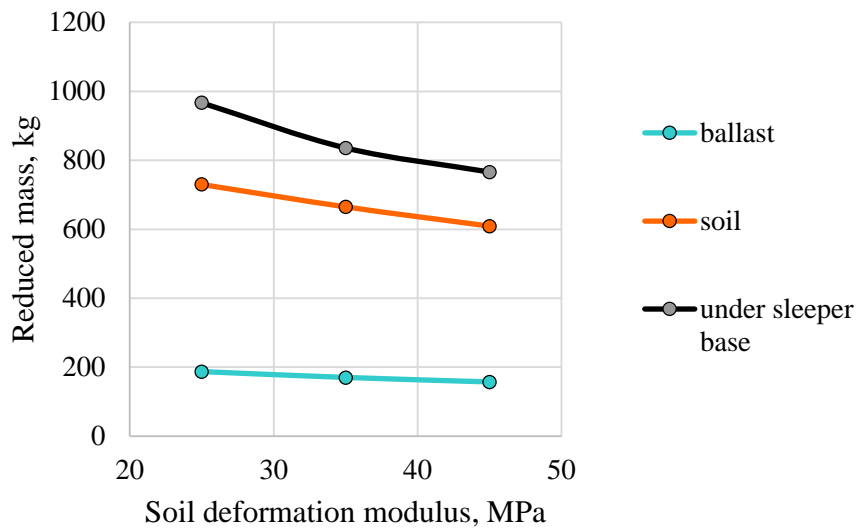

Figure 7. Impact of the soil deformation modulus on the reduced mass

It is understood that increasing the soil deformation modulus reduces its deformations which leads to a decrease in the reduced soil mass. It should be noted that, although with less intensity, but this characteristic also affects the reduced mass 
of the ballast. It is explained by the fact that the soil deformation modulus affects the overall deformability of the railway track, including deformation in the ballast. Thus, if the deformation modulus of the railway track for the basic option (soil deformation modulus is $35 \mathrm{MPa}$ in Fig. 7) was $52.4 \mathrm{MPa}$, then for options with the soil deformation modules of 25 and $45 \mathrm{MPa}$ (while keeping all other initial characteristics) it was 40.6 and $62.6 \mathrm{MPa}$, respectively.

Considering the importance of such a characteristic as the deformation modulus of the railway track, it was determined for each calculation option and will be given in the final results.

\subsection{Soil density}

Options of calculations for different soil density in the range of $1400-1800 \mathrm{~kg} / \mathrm{m}^{3}$ are considered, other characteristics are accepted as in the basic option.

The results of the calculations are shown in Fig. 8.

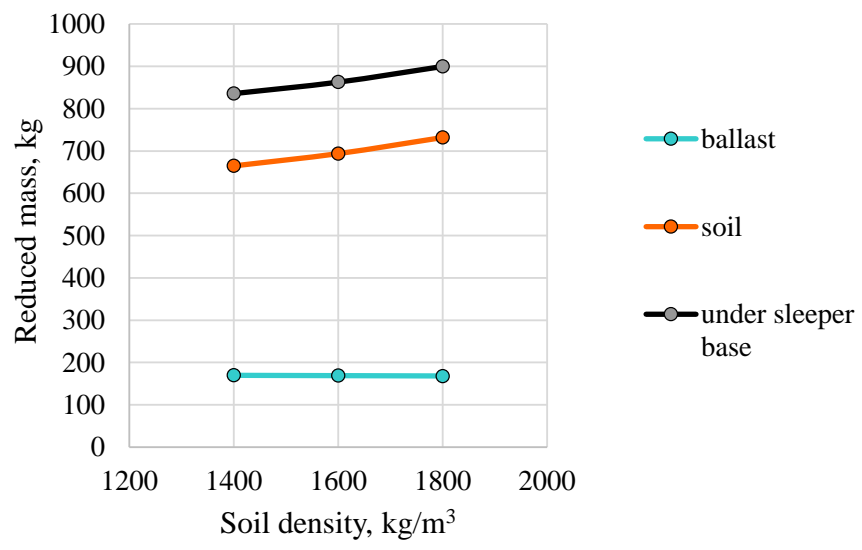

Figure 8. Impact of soil density on the reduced mass

As expected, the increase in soil density, and consequently its bulk density, leads to an increase in the reduced soil mass and, as a consequence, the reduced mass of the track as a whole.

\subsection{Deformation modulus of the ballast}

Let us consider the impact of the deformation modulus of the ballast in the range of 100-200 MPa based on the basic version. The results of the calculations are shown in Fig. 9. 


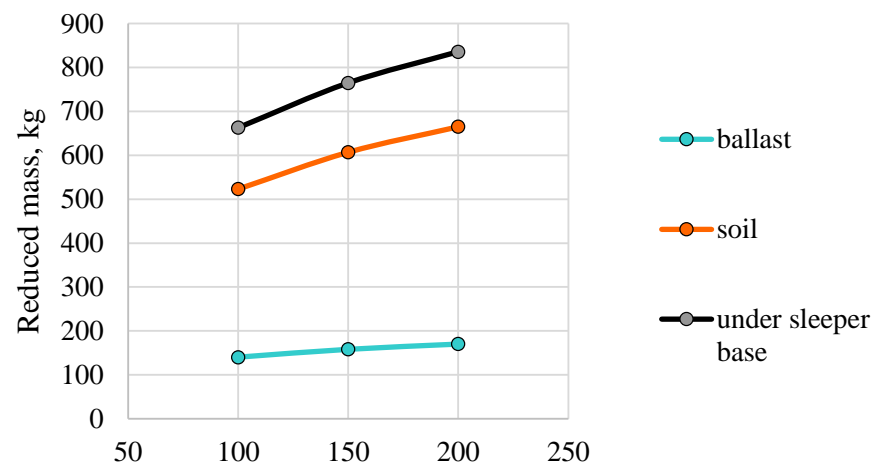

Deformation modulus of the ballast, $\mathrm{MPa}$

Figure 9. Impact of the deformation modulus of the ballast on the reduced mass

As can be seen in Fig. 9, the deformation modulus of the ballast affects both its reduced mass and the reduced soil mass, which is primarily due to changes in the total deformation modulus of the railway track.

\subsection{Ballast density}

The impact of ballast density in the range of $1600-2000 \mathrm{~kg} / \mathrm{m}^{3}$ is shown in Fig. 10.

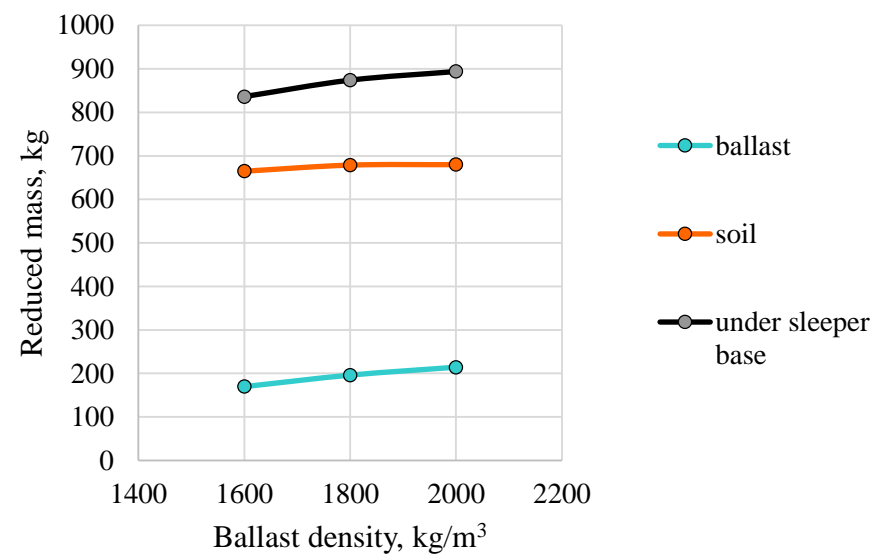

Figure 10. Impact of ballast density on the reduced mass 
An increase in ballast density, as expected, increases its reduced mass, but not significantly, due to the relatively small volumes of the ballast layer involved in the interaction (see Fig. 10).

\subsection{Speed of movement}

The impact of speed on the reduced mass of the railway track will take place in cases of significant differences between dynamic and static deflections. As shown by a large number of studies, at speeds up to $160 \mathrm{~km} / \mathrm{h}$ this effect is absent. Even with a further increase in speed, the difference between dynamic and static deflections appears only in the presence of a rather weak underrail base. At a low value of the deformation modulus of the railway track, physical conditions may occur in which the propagation velocity of deformations will be insufficient to form a complete deflection of the track at a passage time of the wheel.

As mentioned earlier, deformations in the iron track (as in any solid body) propagate at the velocity of elastic waves. This velocity, in turn, depends on such physical characteristics of the environment as the deformation modulus, density, and Poisson's ratio. Moreover, the longitudinal velocity of propagation (in the direction of force) will be greater than the transverse one. For example, for the ballast with a deformation modulus of $200 \mathrm{MPa}$ and a density of $1600 \mathrm{~kg} / \mathrm{m}^{3}$ (basic calculation option), the longitudinal and transverse velocities are $410 \mathrm{~m} / \mathrm{s}^{2}$ and $219 \mathrm{~m} / \mathrm{s}^{2}$, respectively. For soil, especially in the case of weak soils, these velocities will be lower, and for more ballast consolidation, on the contrary, higher. Except in some cases, for example for some peat soils, the velocity of wave propagation is significantly higher than the speed of rolling stock. But a simple comparison of speeds is not indicative of conclusions concerning the sufficiency of time to realize the full deflection of the rail. First, due to the inertia of the process, the realization of complete deformations is delayed in comparison with the propagation of the wavefront. Secondly, and for the railway track, this is an important factor, the implementation of the full deflection of the rail requires not only sufficient depth of deformation in the cross-section of the wheel press but also sufficient propagation along the underrail base under the rail, which should participate in its deflection. Violation of this condition, as a rule, leads to changes in the dynamic deflection at high speeds [20].

Dynamic components of the stress-strain state of the railway track depend on stiffness index of the rail support layers. The lower the deformation modulus, the lower velocity of stress propagation and, as a result, at lower speeds of movement, dynamic effects that go beyond the use of quasi-static calculations can be observed. Therefore the authors consider the impact of travel speed on an example of a weaker design: reinforced concrete sleepers with a density of 1840 pieces $/ \mathrm{km}$, crushed stone 
ballast $50 \mathrm{~cm}$ thick (deformation modulus of the ballast is $100 \mathrm{MPa}$, density is 1600 $\mathrm{kg} / \mathrm{m}^{3}$ ), soil (soil deformation modulus is $10 \mathrm{MPa}$, density is $1400 \mathrm{~kg} / \mathrm{m}^{3}$ ). According to calculations with such initial data, the total deformation modulus of the railway track will be $16.7 \mathrm{MPa}$, at low speeds, the reduced mass of the under sleeper base was $931 \mathrm{~kg}$ ( $217 \mathrm{~kg}$ is the reduced mass of the ballast and $714 \mathrm{~kg}$ is the reduced mass of soil).

As further calculations have shown, the difference in the reduced mass of such an under sleeper base begins to appear with a speed of $240 \mathrm{~km} / \mathrm{h}$ (Fig. 11), and continues to increase with further increase in speed.

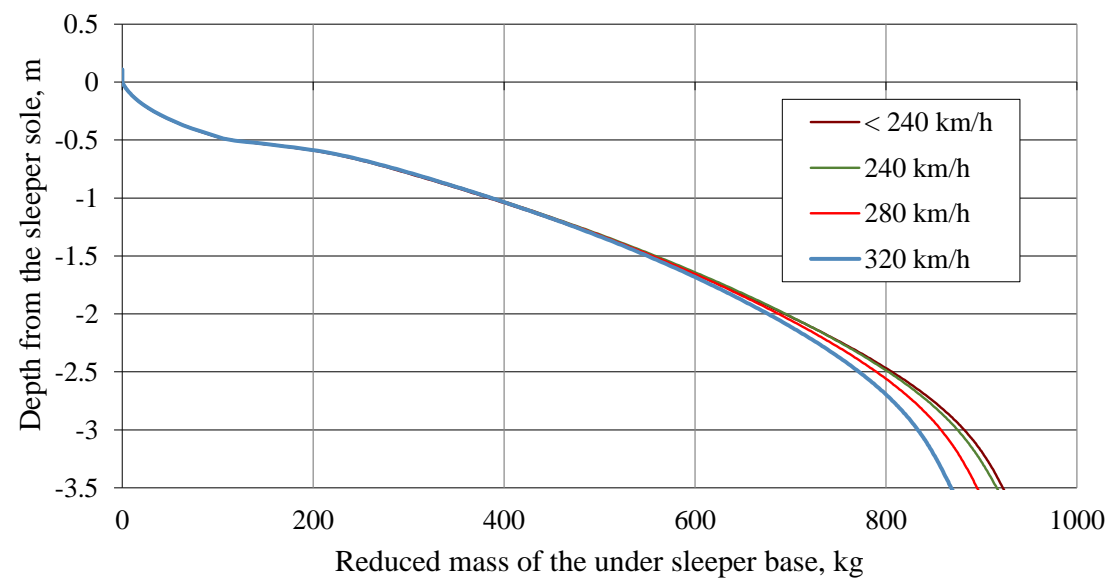

Figure 11. Formation of the reduced mass of the under sleeper base for different levels of speed

Fig. 11 shows that the reduced mass of the under sleeper base decreases in the area of a certain depth of the soil, i.e. where there is a delay of deformation along the rail in front of the wheel [20]. Given that this space - at a certain depth and at a certain distance in front of the wheel - has no significant deformations, their reduction does not lead to significant changes in the reduced mass of the rail base.

\section{Conclusions}

To obtain tools for determining the reduced mass of the under sleeper base taking into account the boundaries of space involved in the oscillations of each rail support at the estimated point in time, a mathematical model of stress-strain operation of the railway based on the elastodynamic problem is applied. 
It is established that the main factors affecting the reduced mass of the under sleeper base are those that determine the deformation characteristics of the railway track, namely: the thickness of the ballast layer, the deformation modulus, and the density of the ballast and the roadbed. The speed of movement has an impact only starting from high levels (from $240 \mathrm{~km} / \mathrm{h}$ and above) for structures with a low deformation modulus of the rail base (from $20 \mathrm{MPa}$ and less).

The main results of variants calculations are given in Tables 1 and 2. These tables allow to reasonably accept the reduced mass of the track (or separately its components) depending on the main characteristics. In the presence of data other than those given in the table, interpolation or extrapolation of the results is possible (see Figures 4-11). So, for a railway track with UIC60 rails on reinforced concrete sleepers depending on values of other characteristics, the reduced mass of support is within $1.1-1.5 \times 10^{3} \mathrm{~kg}$.

Table 1. Results of variants calculations

\begin{tabular}{|c|c|c|c|c|c|c|c|c|}
\hline \multicolumn{5}{|c|}{ Initial date } & \multicolumn{4}{|c|}{ Results } \\
\hline \multicolumn{3}{|c|}{ Ballast } & \multicolumn{2}{|c|}{ Soil } & \multirow[b]{2}{*}{ 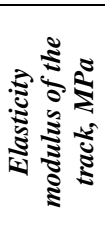 } & \multicolumn{3}{|c|}{ Reduced mass, $\mathrm{kg}$} \\
\hline 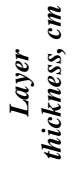 & 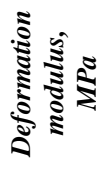 & 胥芯 & 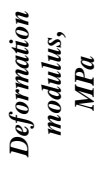 & 预芯 & & 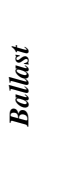 & 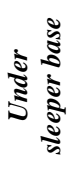 & 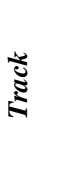 \\
\hline 40 & 200 & 1600 & 35 & 1400 & 48.2 & 115 & 749 & 1180 \\
\hline 50 & 200 & 1600 & 35 & 1400 & 52.4 & 170 & 836 & 1258 \\
\hline 55 & 200 & 1600 & 35 & 1400 & 54.5 & 206 & 886 & 1303 \\
\hline 60 & 200 & 1600 & 35 & 1400 & 56.5 & 235 & 925 & 1339 \\
\hline 50 & 200 & 1600 & 25 & 1400 & 40.6 & 187 & 917 & 1366 \\
\hline 50 & 200 & 1600 & 45 & 1400 & 62.6 & 157 & 766 & 1169 \\
\hline 50 & 200 & 1600 & 35 & 1600 & 53.5 & 169 & 853 & 1272 \\
\hline 50 & 200 & 1600 & 35 & 1800 & 54.4 & 168 & 900 & 1318 \\
\hline 50 & 100 & 1600 & 35 & 1400 & 40.9 & 140 & 663 & 1112 \\
\hline 50 & 150 & 1600 & 35 & 1400 & 47.6 & 158 & 765 & 1197 \\
\hline 50 & 200 & 1800 & 35 & 1400 & 51.3 & 214 & 894 & 1318 \\
\hline 50 & 200 & 2000 & 35 & 1400 & 52.0 & 196 & 874 & 1296 \\
\hline
\end{tabular}


D. Kurhan and Y. Leibuk - Acta Technica Jaurinensis, Vol. 13, No. 4, pp. 324-341, 2020

Table 2. Calculation results with regard to the travel speed

\begin{tabular}{|c|c|c|c|c|c|c|c|c|}
\hline \multicolumn{6}{|c|}{ Initial date } & \multirow{2}{*}{\multicolumn{3}{|c|}{$\begin{array}{c}\text { Results } \\
\text { Reduced mass, } k g\end{array}$}} \\
\hline \multicolumn{3}{|c|}{ Ballast } & \multicolumn{2}{|c|}{ Soil } & \multirow{2}{*}{$\begin{array}{c}\text { Travel } \\
\text { speed, } \\
\mathrm{km} / \mathrm{h}\end{array}$} & & & \\
\hline 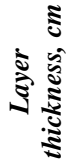 & 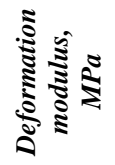 & సิ & 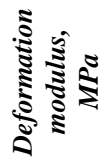 & 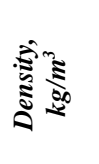 & & 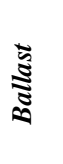 & 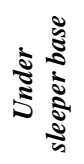 & 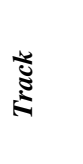 \\
\hline 50 & 100 & 1600 & 10 & 1400 & $<240$ & 217 & 931 & 1492 \\
\hline 50 & 100 & 1600 & 10 & 1400 & 240 & 219 & 925 & 1486 \\
\hline 50 & 100 & 1600 & 10 & 1400 & 280 & 220 & 904 & 1464 \\
\hline 50 & 100 & 1600 & 10 & 1400 & 320 & 220 & 877 & 1436 \\
\hline
\end{tabular}

\section{References}

[1] A. Darenskiy, V. Vitolberg et al, A mathematical model of the rail track presented as a bar on elastic and dissipative supports under the influence of moving loads, Matec Web Conf. 116 (2017) 03002 doi: https://doi.org/10.1051/matecconf/201711603002

[2] M. Esmaeilia, S. Mosayebia, J. Zakeria, Ground-borne vibrations caused by unsupported railway sleepers in ballasted tracks, Procedia Engineering 199 (2017) pp. 2645-2650

doi: https://doi.org/10.1016/j.proeng.2017.09.513

[3] M. Dumitriu, Numerical study of the influence of suspended equipment on ride comfort in high-speed railway vehicles, Scientia Iranica 27 (4) (2020) pp. 1897-1915

doi: https://doi.org/10.24200/sci.2019.50946.1930

[4] B. Yusupov, Y. Qiu, H. Ding, A. Rahman, Temperatureand material behaviour effects on dynamic responses of asphalt concrete trackbed, InternationalJournal of Rail Transportation 8 (1) (2020) pp.66-79 doi: https://doi.org/10.1080/23248378.2019.1628671

[5] D. Milne, J. Harkness et al, The influence of variation in track level and support system stiffness over longer lengths of track for track performance and vehicle track interaction, Vehicle System Dynamics (2019) doi: https://doi.org/10.1080/00423114.2019.1677920 
[6] M. A. Spiroiu, C. I. Crăciun, Wheel flat effect on wheel-rail dynamic interaction, IOP Conf. Ser.: Mater. Sci. Eng. 444 (2018) 042002 doi: https://doi.org/10.1088/1757-899X/444/4/042002

[7] B. Eller, S. Fischer, Review of the modern ballasted railway tracks' substructure and further investigations, Science and Transport Progress 6 (84) (2019) pp. 72-85 doi: https://doi.org/10.15802/stp2019/195831

[8] A. Németh, Z. Major, S. Fischer, FEM Modelling Possibilities of Glued Insulated Rail Joints for CWR Tracks, Acta Technica Jaurinensis 13 (1) (2020) pp. 42-84

doi: https://doi.org/10.14513/actatechjaur.v13.n1.535

[9] A. Radkevych, V. Petrenko et al, Comparative analysis of the parameters of the strength of the subgrade at the transition to the higher axial loading up to 25 t, IOP Conf. Ser.: Mater. Sci. Eng. 708 (2019) 012024 doi: https://doi.org/10.1088/1757-899X/708/1/012024

[10] E. Juhász, S. Fischer, Investigation of railroad ballast particle breakage, Pollack Periodica Pollack Periodica, 14 (2) (2019) pp. 3-14. doi: https://doi.org/10.1556/606.2019.14.2.1

[11] E. Juhász, R. M. Movahedi et al, Discrete elemet modelling of particle degardation of railway ballast material with PFC3D software, Science and Transport Progress 6 (84) (2019) pp. 103-116 doi: https://doi.org/10.15802/stp2019/194472

[12] M. Sysyn, V. Kovalchuk et al, Experimental study of railway ballast consolidation inhomogeneity under vibration loading, Pollack Periodica 15 (1) (2020) pp. 27-36 doi: https://doi.org/10.1556/606.2020.15.1.3

[13] D. Kurhan, M. Kurhan, Modeling the Dynamic Response of Railway Track, IOP Conf. Ser.: Mater. Sci. Eng. 708 (2019) 012013 doi: https://doi.org/10.1088/1757-899X/708/1/012013

[14] E. Juhász, S. Fischer, Railroad Ballast Particle Breakage with Unique Laboratory Test Method, Acta Technica Jaurinensis 12 (1) (2019) pp. 26-54 doi: https://doi.org/10.14513/actatechjaur.v12.n1.489 
[15] Y. Leibuk, A. Scoryk et al, Experimental Determination of The Arrayed Mass of The Track, Bridges and tunnels: theory, research, practice 15 (2019) pp. 41-46, in Ukranian

[16] D. Kurhan, Determination of load for quasi-static calculations of railway track stress-strain state, Acta Technica Jaurinensis 9 (1) (2016) pp. 83-96 doi: https://doi.org/10.14513/actatechjaur.v9.n1.400

[17] M. Sysyn, U. Gerber et al, The complex phenomenological model for prediction of inhomogeneous deformations of railway ballast layer after tamping works, Archives of Transport 47 (3) (2018) pp. 91-107 doi: https://doi.org/10.5604/01.3001.0012.6512

[18] A. Shvets, Determination of The Stability of Freight Cars Taking Into Account The Railway Track Parameters, Science and Transport Progress 86 (2) (2020) pp. 103-118, in Ukranian doi: https://doi.org/10.15802/stp2020/203421

[19] D. Kurhan, The basis of mathematical description for wave model of stresses propagation in railway track, Science and Transport Progress 65 (5) (2016) pp. 101-113, in Ukranian doi: https://doi.org/10.15802/stp2016/84032

[20] D. Kurhan, Features of perception of loading elements of the railway track at high speeds of the movement, Science and Transport Progress 56 (2) (2015) pp. $130-145$

doi: https://doi.org/10.15802/stp2015/42172 